\title{
GEODIVERSIDADE NA BACIA HIDROGRÁFICA DO RIO TENENTE AMARAL - MT
}

\author{
Geodiversity in the hydrographic basin of the River Tenente Amaral - MT
}

\begin{abstract}
Cleberson Ribeiro de Jesuz Professor do Departamento de Geografia da Universidade Federal de Mato Grosso- UFMT clebersonjesuz@ufmt.br

Ingrid Regina da Silva Santos Professora interina da Secretaria de Estado de Educação de Mato Grosso - SEDUC-MT insantosgeo@gmail.com
\end{abstract}

Aceito: $07 / 07 / 2020$

Recebido: 18/06/2020

RESUMO: As intervenções das últimas décadas dos agentes sociais na constituição dos aspectos naturais se tornam cada dia mais intenso e danoso para o resguardo dos patrimônios geológicos, isto é, da geodiversidade terrestre. Assim, propõe-se em escala de bacia hidrográfica determinar os principais pontos de geodiversidade de um determinado território no sudeste do estado de Mato Grosso, a bacia do rio Tenente Amaral, utilizando de técnicas de sensoriamento remoto e geoprocessamento foram levantados cerca de 48 possíveis pontos de interesse. Que devido as suas características naturais foram divididas em três momentos, quedas d'água/aproveitamento energético, cachoeiras/ecoturismo e escarpas/afloramentos rochosos. Os principais resultados obtidos ainda que preliminares apontam que os patrimônios analisados necessitam de maiores levantamentos, e práticas de estudos/conhecimentos para determinar ações de resguardo e proteção por serem importantes para a vida social dos habitantes, e com grande apelo a ações de turismo.

Palavras-chave: Análise integrada; Geografia; Feições geomorfológicas.

ABSTRACT: The interventions of the last decades of the social agents in the constitution of the natural aspects become increasingly intense and harmful for the protection of the geological heritages, in other words, of terrestrial geodiversity. Thus, a basin scale is proposed to determine the main geodiversity points of a designated territory in the southeast of the state of Mato Grosso, the TenenteAmaral river basin, using remote sensing and geoprocessing techniques were collected about 48 possible points of interest. Those due to their natural characteristics were divided in three moments, waterfalls / energy use, waterfalls / ecotourism and rock escarpments / outcrops. The main results obtained, although preliminary, indicate that the analyzed assets require higher surveys, and studies / knowledge practices to determine preservation and protection actions because they are important for the social life of the inhabitants, and with great appeal to tourism actions.

Keywords: Integrated analysis; Geography; Geomorphological. 


\section{INTRODUÇÃO}

A apropriação das paisagens naturais para o uso urbano e agrícola alcançou, nos últimos dois séculos, taxas nunca antes vistas, com um aumento populacional humano de mais de $700 \%$, decorrentes das interações propiciadas pela qualificação e quantificação dos avanços da tecnologia e ciência (ALVES, 2008; SILVA et al., 2010).

Dessa forma, esse ritmo de subversão da natureza vem alastrando fenômenos de desequilíbrio entre os ambientes, e consequentemente afetando a vida humana de forma direta e/ou indiretamente, por meio de desastres ambientais, propagação de vetores de doenças, desequilíbrios de temperatura e pluviosidade local e regional, entre outras consequências (DREW, 1986; LAMBIN et al., 2013).

Essa situação provoca conforme Souza et al., (2016), uma atenção focada nas ideias de conservação da natureza, instituídas principalmente pelos pesquisadores e agências governamentais, com grande concentração nas determinantes da Biodiversidade, ou seja, a diversidade biológica, ignorando de modo abrupto os estudos geológicos e geomorfológicos, isto é, as características estruturais do planeta.

Entre os mais diversos conceitos empregados na compreensão dessa realidade vasta e dinâmica o de geodiversidade é um dos que mais contempla sua magnitude, pois como afirma Brilha (2005), ela se pauta na interação de diversos fatores, como as rochas, o clima, a biota e, outros elementos, possibilitando o aparecimento de paisagens distintas em todo o mundo.

Gray (2013, p. 12), apresenta uma das definições mais conhecidas e adotadas pelos estudiosos do conceito, onde o autor expõe que geodiversidade é "a variedade natural (diversidade) defeições geológicas (rochas, minerais, fósseis), geomorfológicas (geoformas, topografia, processos físicos), pedológicas e hidrográficas. Isso inclui suas assembléias, estruturas, sistemas e contribuições para a paisagem".

O Serviço Geológico do Brasil - CPRM, define a geodiversidade como a,

[...] natureza abiótica (meio físico) constituída por uma variedade de ambientes, fenômenos e processos geológicos que dão origem às paisagens, rochas, minerais, solos, águas, fósseis e outros depósitos superficiais que propiciam o desenvolvimento da vida na Terra, tendo como valores a cultura, o estético, o econômico, o científico, o educativo e o turístico (CPRM, 2008, p. 38).

Dessa forma, Pereira e Ruchkys (2016, pags. 210 e 211), debatem que a geodiveridade,

[...] tem várias aplicações permitindo, por exemplo, identificar em um dado território, áreas prioritárias para geoconservação ou com maior potencial para o desenvolvimento do geoturismo, segmento do turismo que faz uso do geopatrimônio como atrativo.

Nesse esteio, tem-se o patrimônio geológico brasileiro que é extremamente vasto, mas pouco conhecido por grande parte da sua própria população e comunidade científica em geral, fato explicado muitas vezes, por sua grande extensão territorial, 
dificuldade em acesso a pontos/áreas especifica e, incipientes trabalhos científicoacadêmicos em âmbito nacional de integralização (OLIVEIRA et al., 2013; BENTO e RODRIGUES, 2013; SILVA e GÂNDARA, 2014; FONTANA et al., 2015).

A ideia do patrimônio geológico fora incorporada por diversos estudiosos, sendo mais bem definida no conceito de geopatrimônio, que de acordo com Delphin, (2009) possui caráter material e imaterial, sendo os geossítios sua expressão palpável e os valores atribuídos a estes, o impalpável. Assim como, em Borba (2011, p. 6), que apresenta o geopatrimônio como "componentes da geodiversidade importantes para a humanidade por razões outras que não a extração de recursos, e cuja preservação é desejável para as atuais e futuras gerações".

Portanto, compreender a geodiversidade, e mais especificamente o patrimônio geológico, é salvaguardar a história da evolução da Terra, e nessa perspectiva o viés de melhor resultados, deve ser o da geoconservação. Sendo que, nas palavras de Brilha, (2005, p. 51) geoconservação é "um ramo de atividade científica que tem como objetivo a caracterização, conservação e gestão do patrimônio geológico e processos naturais associados". E, conforme Pereira et al., (2016, p. 202), onde a,

\begin{abstract}
[...] geoconservação almeja a identificação e conservação do patrimônio geológico de um território, sendo produto do um inventário da sua geodiversidade. Considerando os diversos usos do patrimônio natural pelas sociedades humanas, e que os elementos abióticos da natureza, muitas vezes, são dotados de valor econômico e carente de ações efetivas de conservação e proteção, a difusão das práticas geoconservacionistas são uma necessidade sócio cultural premente.
\end{abstract}

Nesta perspectiva, Nascimento et al., (2008, p. 21) debatem que "o patrimônio geológico não é renovável e, uma vez destruído, não se regenera e parte da memória da Terra é perdida para sempre", apontando assim a importância da geoconservação. $\mathrm{E}$, que uma das ideias mais concisas para integralizar esses argumentos, é o geoturismo, compreendido "como parte de um manejo holístico considerando a interrelação do patrimônio geológico com os patrimônios cultural e biológico" (NASCIMENTO et al., 2008, pg. 32).

Dessa forma, objetiva-se com essa discussão compreender preliminarmente a geodiversidade encontrada em um recorte geográfico de bacia hidrográfica, a do Rio Tenente Amaral no sul do estado de Mato Grosso, de forma a subsidiar uma primeira aproximação entre 0 trinômio conceitual: geodiversidade-geoconservaçãogeoturismo.

Essa aproximação inicial é fundamental para o entendimento das situações encontradas na bacia do Tenente Amaral, devido a sua intensa exploração comercial, de cunho agropecuário e produção de energia por meio de Pequenas Centrais Hidrelétricas, instaladas preferencialmente em áreas chaves de valor patrimonial, sejam os vales encaixados e/ou com quedas d'água. Portanto, buscar uma nova visão sobre essa bacia hidrográfica se consolida como iniciativa a melhor formulação da compreensão das determinantes físico-bióticas desse território, testemunho da atuação severa de desgaste e remoção da geodiversidade presente e pretérita. 


\section{MATERIAIS E MÉTODOS}

\section{Área de estudo}

Este estudo foi realizado em um recorte espacial, localizado em sua maior extensão no município de Jaciara, porção sul do estado de Mato Grosso, cerca de $150 \mathrm{~km}$ da capital, Cuiabá, denominado de bacia hidrográfica do Rio Tenente Amaral.

A bacia hidrográfica do rio Tenente Amaral, faz parte do sistema São Lourenço/Cuiabá. Sendo uma área do alto curso do setor nordeste da bacia hidrográfica do rio Paraguai, perfazendo uma das parcelas do sistema do entorno da parte norte da Planície do Pantanal.

O sistema São Lourenço tem grande parte dos seus tributários localizados nas superfícies do Planalto e Chapada dos Guimarães e Depressão Interplanáltica de Rondonópolis. Estas unidades, no contexto regional evolutivo do conjunto de formas do relevo, passaram por vários eventos da dinâmica própria das bacias de sedimentação em ambiente geológico de "estabilidade" onde, ao longo da sua história geológica os eventos da morfodinâmica promoveram o reafeiçoamento cíclico do modelado, expressado pelas duas unidades de relevo em questão.

A área da bacia hidrográfica do rio Tenente Amaral localiza-se a $120 \mathrm{Km}$ a leste da

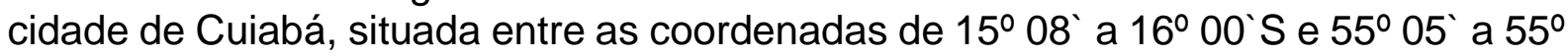
$35 \mathrm{~W}$, apresentando uma área de $859 \mathrm{Km}^{2}$. Seu sistema é formado pelos rios Brilhante, Cachoeirinha e Saia Branca, conforme representado no mapa da figura 1.

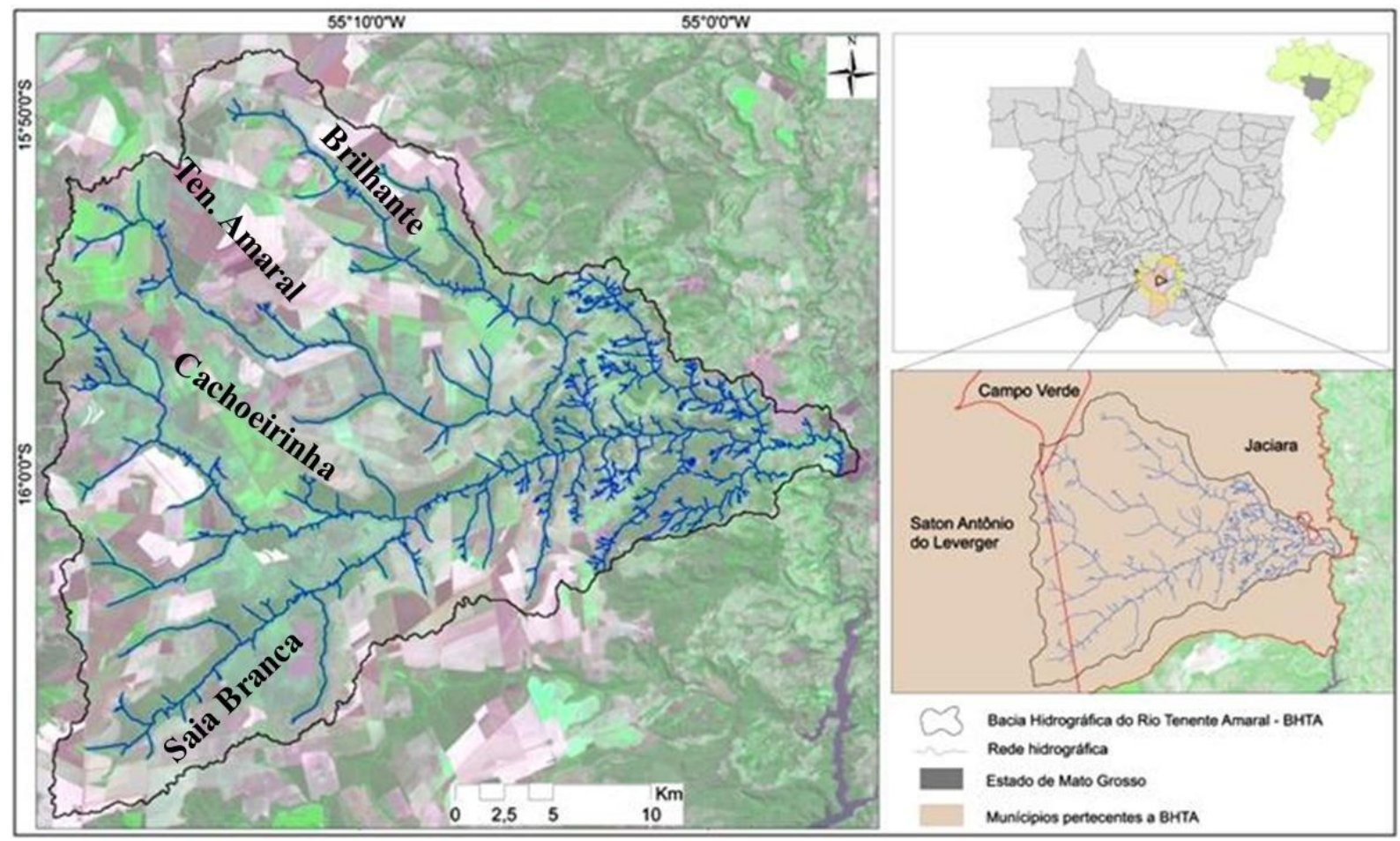

Figura 1 - Bacia hidrográfica do rio Tenente Amaral - MT. Fonte: SEPLAN - MT, 2007. 
Em termos de ambiente, de acordo com Tarifa (2011), a superfícies da bacia hidrográfica em questão faz parte da macrounidade climática do tipo Clima Tropical Continental Alternadamente Úmido e Seco das Chapadas, Planaltos e Depressões de Mato Grosso, levando em consideração a regularidade cíclica de alternância do movimento estacional quente e úmido; a existência de um conjunto de substancial de terras elevadas nos níveis entre 400 a 800 metros; e o posicionamento do modelado do terreno - Planalto, Depressões e Planícies - que promovem o maior controle na ciclicidade das enchentes e secas em cada uma destas unidades morfoesculturais.

$E$, referente aos compostos fitogeográficos esta é uma das superfícies onde se destacam os compostos vegetais do Cerrado (BRASIL, 1982; VASCONCELOS, 1998). Esta composição apresenta diversidade associada às condições dos solos que, em termos gerais estão representados pelos Neossolos Quartzarênicos, Latossolos Vermelho, Latossolos Vermelho Amarelo, Argissolos e os solos Hidromórficos nos fundos dos vales (JESUZ e CABRAL, 2016).

Em termos litológicos a área da bacia hidrográfica do rio Tenente Amaral faz parte da unidade morfoestrutural da Bacia Sedimentar do Paraná, representada pelas Superfícies Paleogênica Peneplanizada com Latolização (Terciário), arenitos ortoquartzíticos de granulometria grosseira da Formação Furnas (Devoniano) e arenitos finos com registros esporádicos de arenitos grosseiros e conglomeráticos em sua base, da Formação Grupo Rio Ivaí (Ordivício-Siluriano) (CAMARGO, 2011).

As superfícies da bacia hidrográfica do rio Tenente Amaral fazem parte da unidade geomorfológica do Planalto dos Guimarães, onde prevalece o conjunto de formas Convexas e os Patamares Estruturais, sob diferentes ordens de grandeza e dissecação da drenagem. Nestas áreas a ação vertical desempenhada pelo sistema de drenagem constitui um dos principais processos situados ao longo dos eixos da drenagem principal (BRASIL, 1982 e CAMARGO, 2011).

Outra abordagem em relação às condições do relevo na área da bacia é a proposta apresentada por Latrubesse et. al., (1998). Nesta proposta sobre o relevo do estado de Mato Grosso as superfícies da bacia hidrográfica do rio Tenente Amaral são explicadas a partir das proposições estabelecidas para o Sistema Denudacional com formas de relevo em continuo processo geral de esculturação.

Essas condições, junto com os fatores intrínsecos à produção geográfica do espaço brasileiro e do próprio Estado, promoveram inúmeras mudanças nas condições "originais" na região e, por sua vez na área deste sistema de drenagem. Dentre as várias intervenções as que mais se destacam são aquelas relacionadas à prática da agricultura mecanizada para desempenhar o cultivo da soja, milho, algodão, cana de açúcar, pecuária de corte e leiteira (WWF BRASIL, 2015).

\section{Procedimentos técnico-operacionais}

A imprescindibilidade de solidez na compreensão da geodiversidade da bacia hidrográfica do Rio Tenente Amaral induz a procedimentos técnico-operacionais capazes de suplantar essa necessidade. Assim, utilizando-se de uma base cartográfica oficial do Estado de Mato Grosso, e dados disponibilizados por outros 
órgãos, foram feitas correções escalares, de modo a se igualarem aos dados geomorfológicos, que apresentam escala de detalhe (JESUZ e CABRAL, 2016).

Dessa maneira, os dados cartográficos, associados aos estudos teóricometodológicos (Fig.2), forneceram uma base conceitual e técnica para identificar de forma preliminar os aspectos da geodiversidade da área analisada, e subsidiar a discussão proposta.

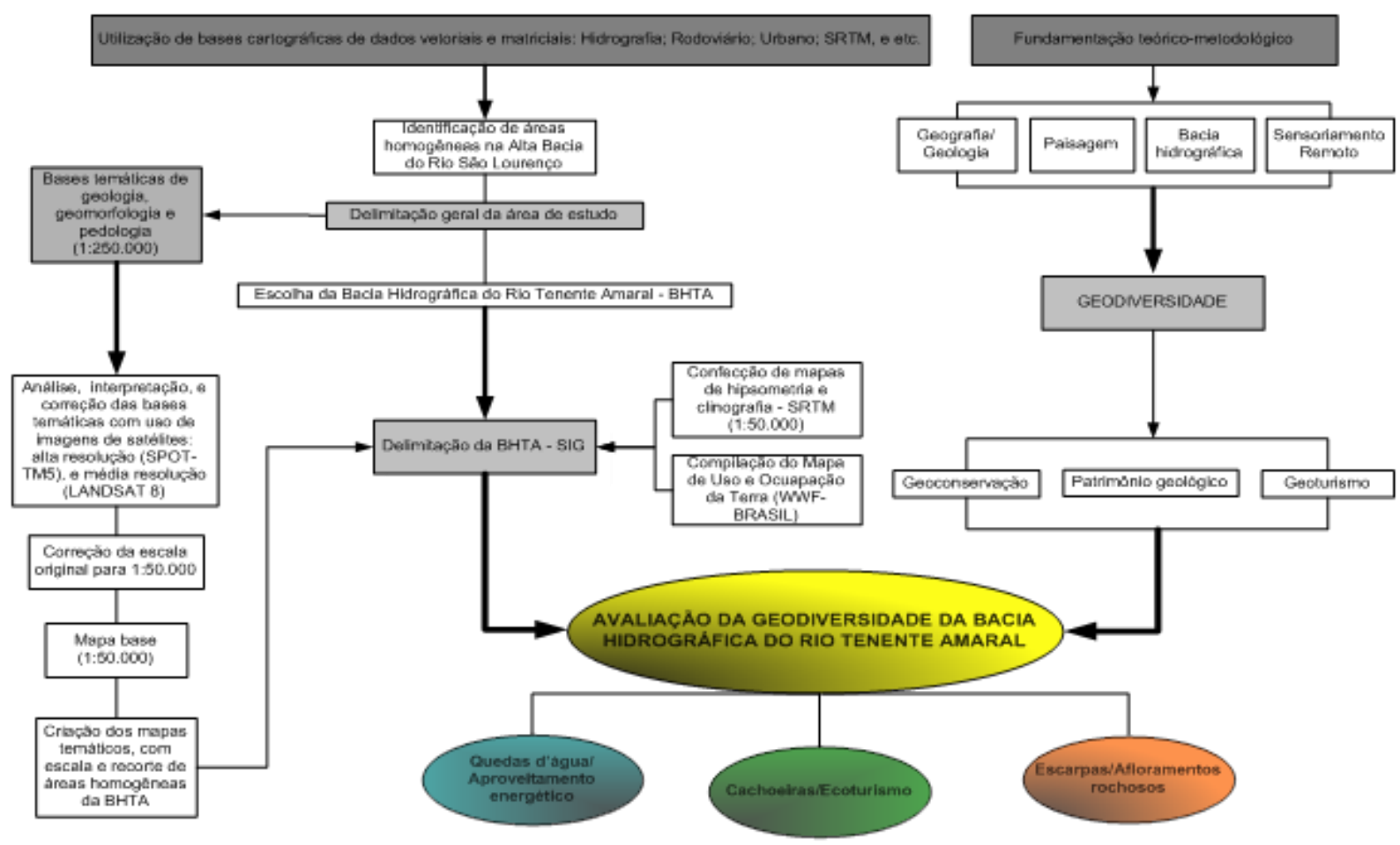

Figura 2 - Fluxograma dos procedimentos adotados. Fonte: Autores.

\section{RESULTADOS E DISCUSSÃO}

A cartografia de base levantada e refeita para a bacia hidrográfica do rio Tenente Amaral foi necessária para avaliar o comportamento dos três principais eixos dessa discussão, as quedas d'água/aproveitamento energético, cachoeiras/ecoturismo e escarpas/afloramentos rochosos (Fig. 3). 


\section{Di: REVISTA GEONORTE}
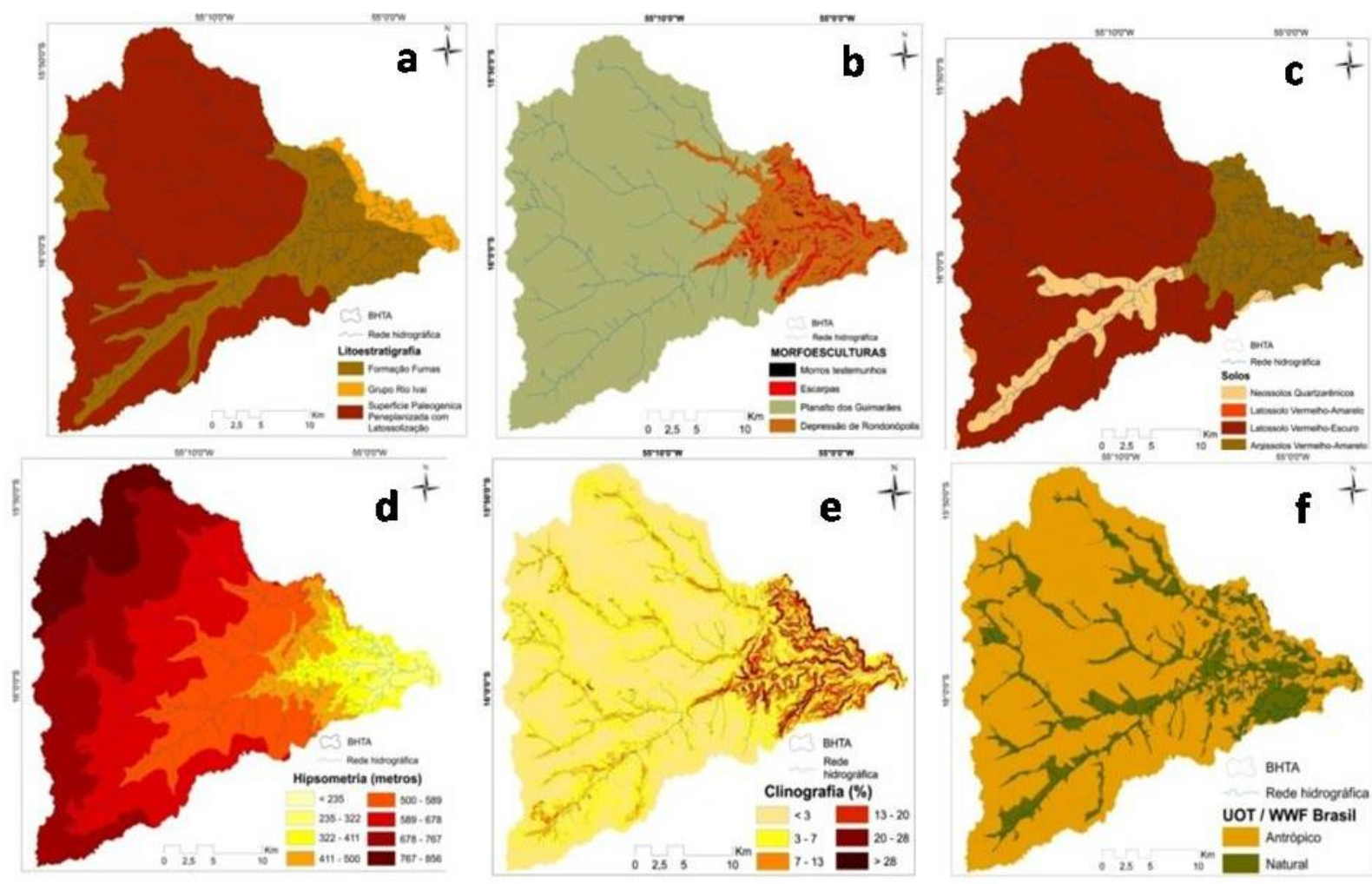

Figura 3 - Mapas-bases da bacia hidrográfica do Rio Tenente Amaral. Legenda: a) Litoestratigrafia; b) Geomorfologia; c) Solos; d) Hipsometria; e) Clinografia; e f) Uso e Ocupação da terra. Organização: Autores.

Assim, como o objetivo principal é possibilitar uma leitura preliminar da geodiversidade da bacia e, como esses patrimônios são vistos e usados pela sociedade, tem-se que, em um primeiro momento é fundamental o entendimento das características físicas e da ação social, de modo a se pensar numa geoconservação e geoturísmo, partido da espacialização desses pontos na paisagem, de forma que foram levantados ao todo 48 possíveis pontos com boa caracterização da geodiversidade, sendo em sua grande maioria patrimônios geomorfológicos, tanto em questão de quedas d'água e cachoeiras, e estruturas do relevo (Fig.4). 


\section{REVISTA GEONORTE}

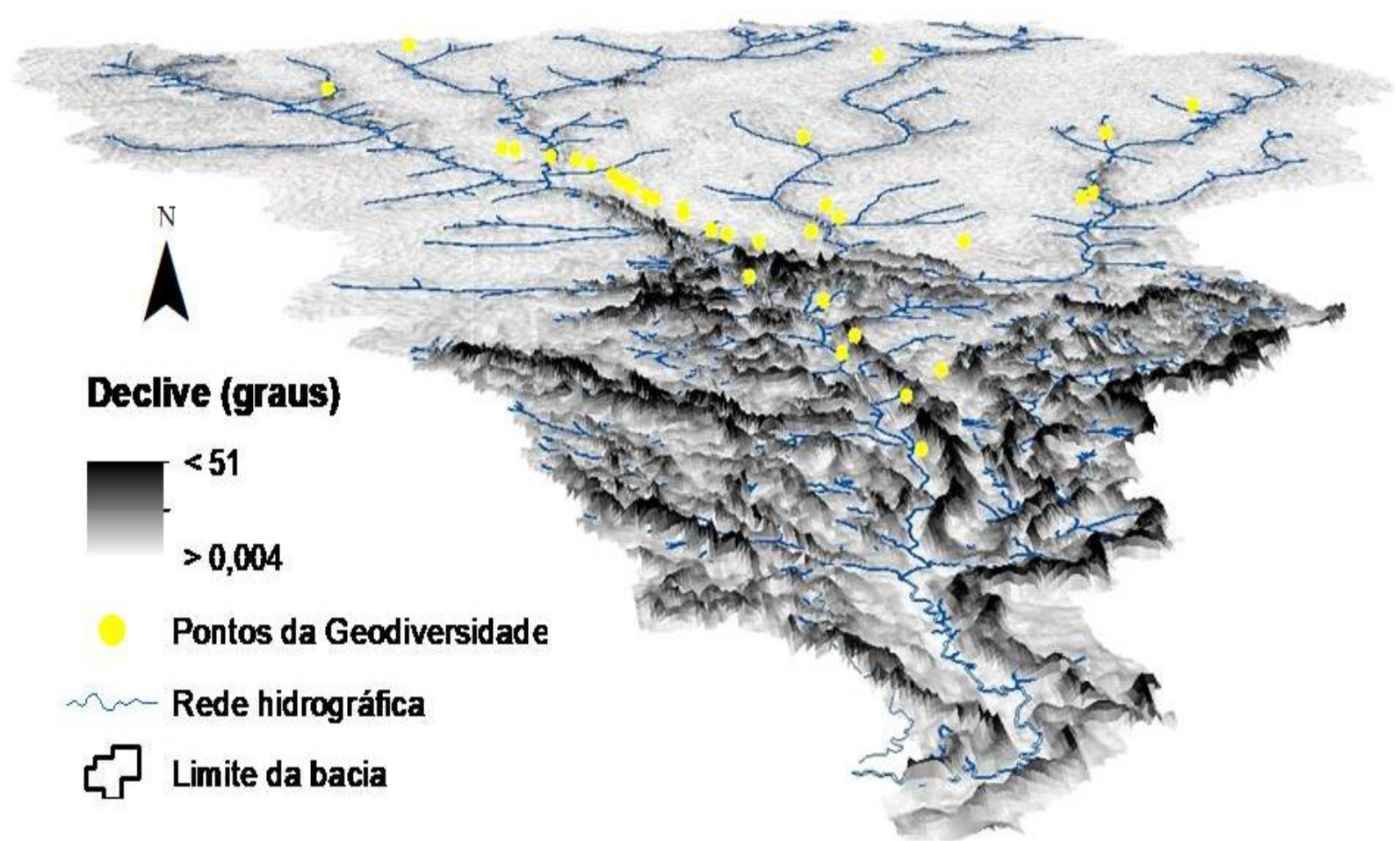

Figura 4 - Espacialização tridimensional dos principais pontos com possíveis elementos da geodiversidade. Fonte: Autores.

Dessa maneira, espacializar as áreas com algum vinculopossibilistico de geodiveridade é fundamental para essa discussão e, de modo concreto viabilizar as principais categorias e características dentro das capaciades de geoconservação e geoturismo desses pontos levantados. Em que, a contribuição posta surja efeitos no entendimento das reiais situações destes em consonância com os termos abordados.

As áreas com quedas d'água localizam-se principalmnte na morfoescultura do Planalto dos Guimarães em parcelas com solos na transição latossolos/gleissolos, declives suaves de até $7 \%$, e altitudes de $450-800 \mathrm{~m}$. A litoestatrigrafia predominante é o da Formação Furnas, com alguns pontos sobre a Superficie Paleogênica Peneplanizada de Latolização (Fig. 5). 


\section{DUe REVISTA GEONORTE}

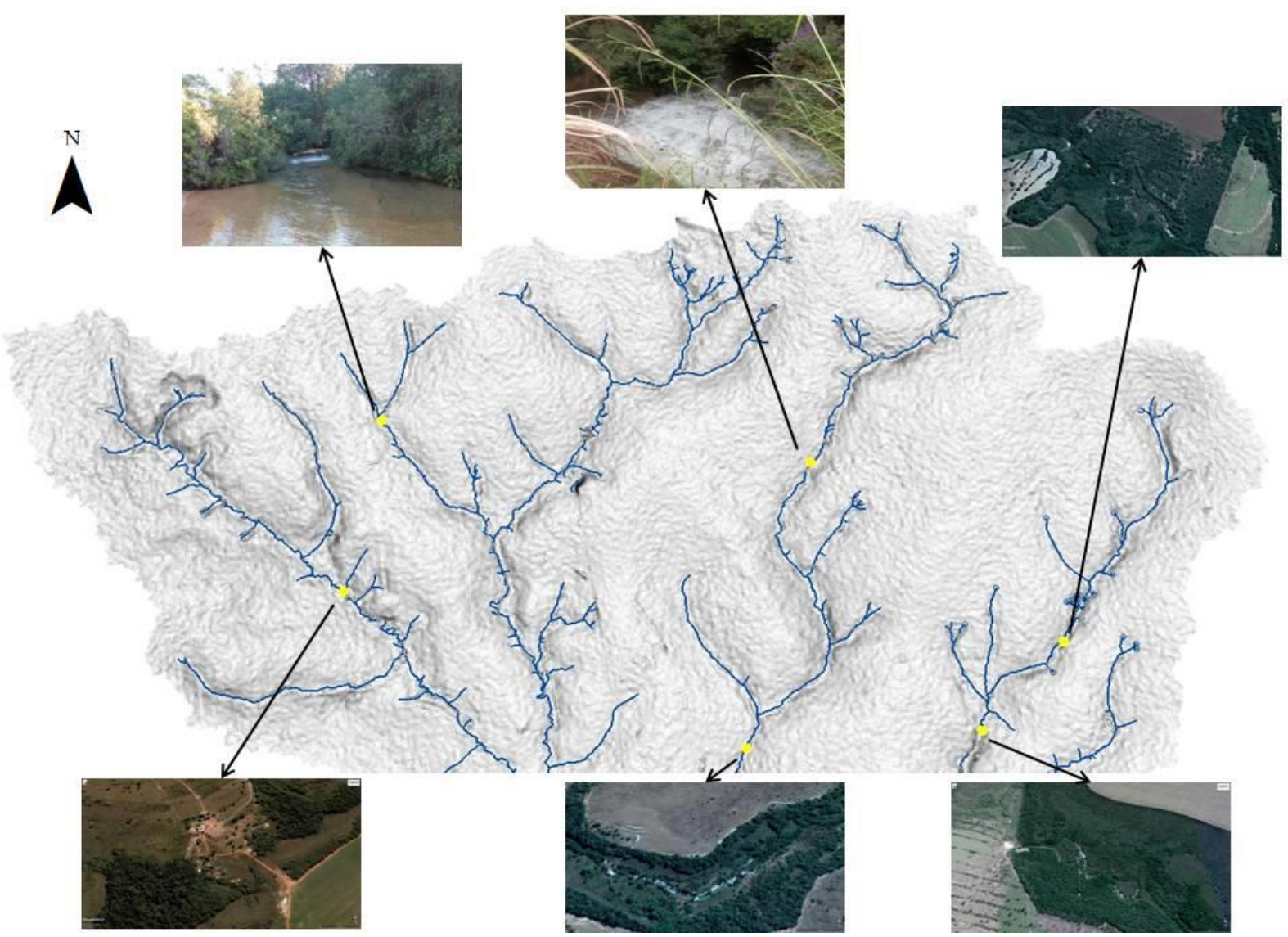

Figura 5 - Distribuição dos pontos com quedas d'águas no Planalto dos Guimarães.

Fonte: Autores.

O que observa como maior clareza nesses pontos de queda d'águas na parte da morfoescultura do Planalto dos Guimarães é a presença dessas geodiversidade em cursos d'água de maior fluxo. Sua posição geográfica in situ em áreas do agronegócio favorece possibilidades intensas de degradação e ações de mudança na paisagem, especialmente pelo represamento e redirecionamento dos cursos d'água para abastecimento de áreas com pivôs e pequenos açudes/represas de uso bovino/eqüino/caprino e outros (Fig. 6).

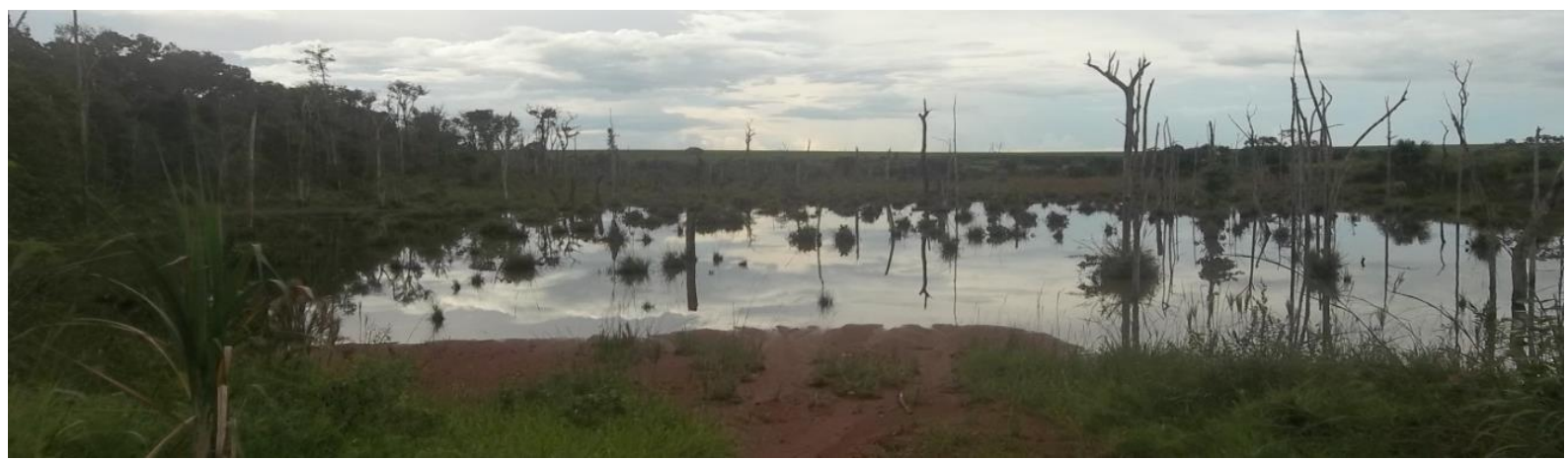

Figura 6 - Área com represamento para uso agropecuário. Fonte: Autores. 
Uma das soluções possíveis para favorecer a compreensão e denotação dos patrimônios levantados para esses pontos seria o emprego de ações voltadas ao turismo de base rural, que possibilitariam a médio e longo prazo, favorecer estudos e iniciativas de vinculação geoconservacionista e geoturística desses locais.

Nesse esteio, Brasil (2010, p. 18), relata que o turismo de base rural é, "o conjunto de atividades turísticas desenvolvidas no meio rural, comprometido com a produção agropecuária, agregando valor a produtos e serviços, resgatando e promovendo o patrimônio cultural e natural da comunidade". Portanto, caberia uma forte iniciativa de proteção dos elementos naturais e maiores estudos sobre suas características e possibilidades de integralização nas ações turísticas e vivencia cotidiana da sociedade local/regional.

Por outro lado, as PCHs, estão dispostas espacialmente na parcela de transição das morfoesculturas do Planalto dos Guimarães e a Depressão Interplánaltica de Rondonópolis, devido à mudança hipsométrica abrupta, e a disposição do modelado que permite aproveitar as formas do relevo com áreas de tanques naturais (Fig. 7).

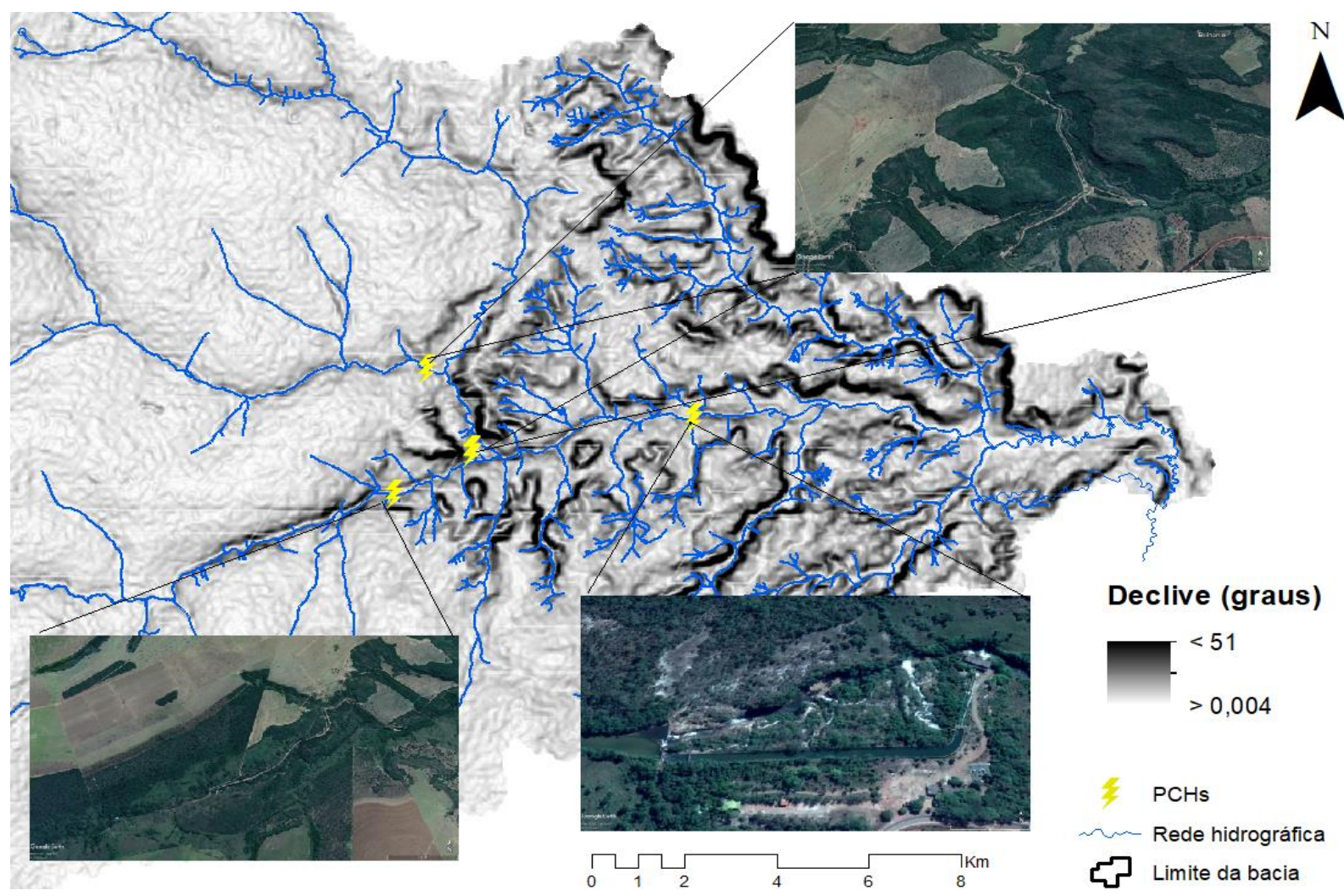

Figura 7 - Distribuição das Pequenas Centrais Hidrelétricas na bacia hidrográfica do Rio Tenente Amaral. Fonte: Autores.

Os pontos-chaves observados de geodiversidade de cachoeiras e cachoeiras com turismo, isto é, o ecoturismo. Onde segundo, López-Richard e Chináglia (2004, p. 202), o ecoturismo deve, 
[...] ser a atividade turística que visa minimizar o impacto no meio ambiente no qual se desenvolve, priorizando a proteção e a conservação sustentável dos recursos ambientais (naturais, culturais, históricos etc.), bem como a contribuição para o bem-estar econômico e social da comunidade, resultado da interação e da coexistência harmoniosa entre esta e a atividade eco turística.

Dessa forma, as práticas dos usuários desses pontos levantados na bacia hidrográfica do Rio Tenente Amaral, incluem-se nas que derivam de ações diretas de observação, interação e uso dos recursos naturais disponíveis, sejam eles, água, corredeiras, cachoeiras ou esportes de turismo de aventura (para a realidade proposta rafting, rafting noturno, boiacross, cachoeirismo, rapel, trilhas e caminhadas) (Fig. 8).
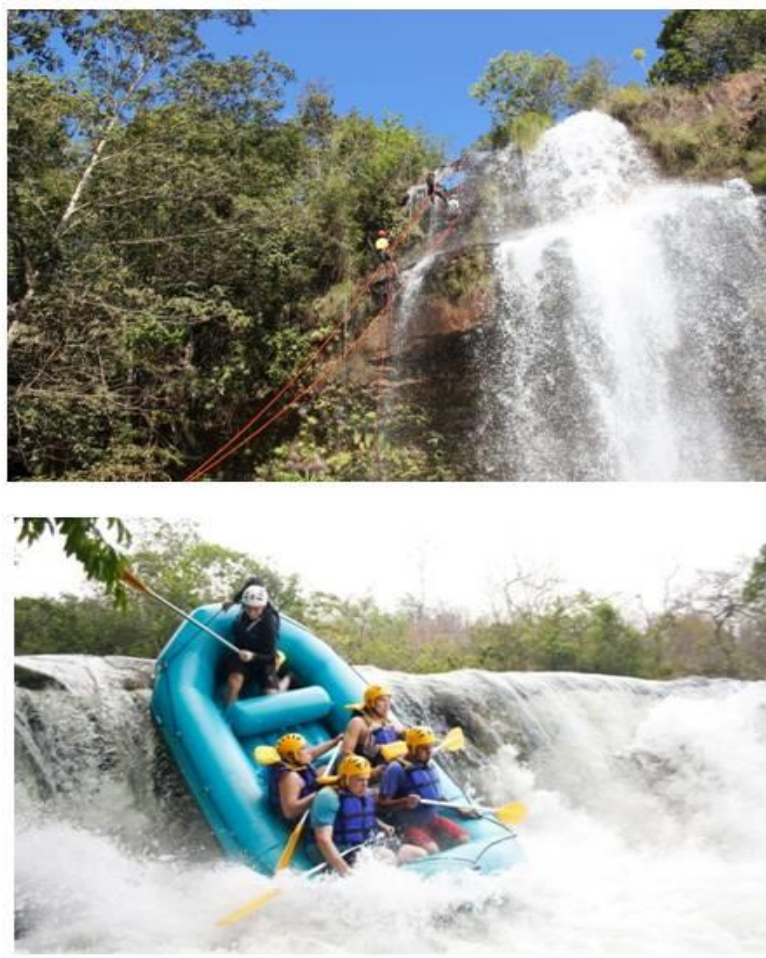

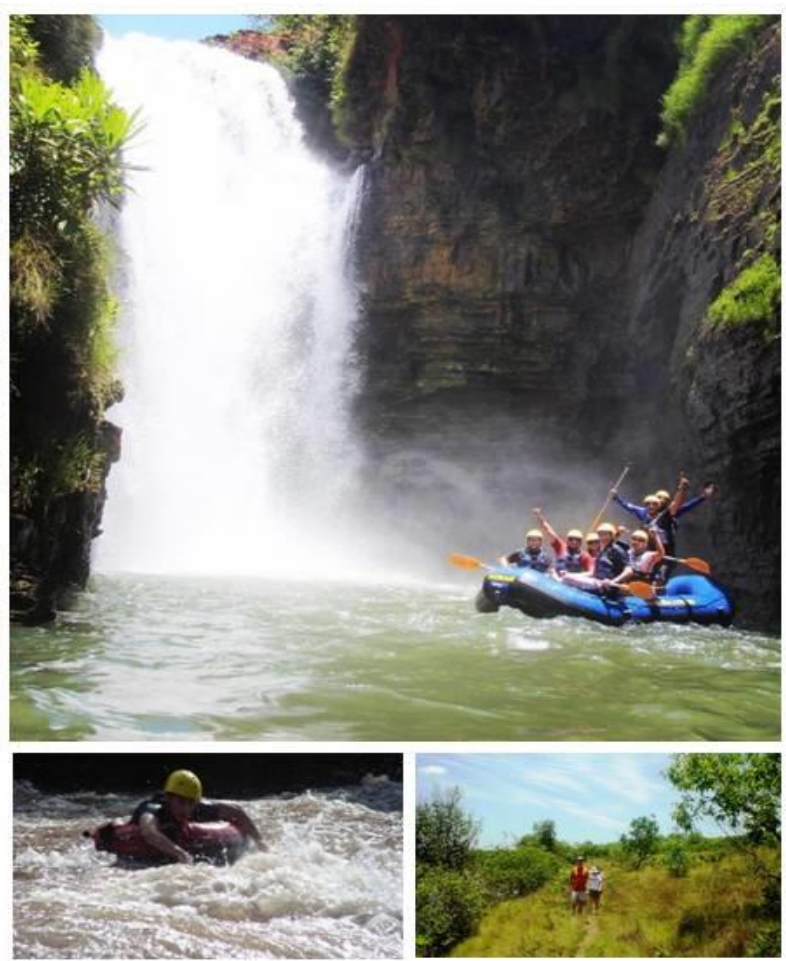

Figura 8 - Mosaico com as principais práticas do ecoturismo, incluindo o turismo de aventura. Fonte: Ararauna Turismo (https:<//araraunaturismo.com.br/?tour=jaciara $>$ ).

Os principais pontos da geodiversidade com foco no patrimônio geomorfológico de cachoeiras (com e sem uso do ecoturismo) encontram-se na transição entre as morfoesculturas do Planalto dos Guimarães e a Depressão Interplánaltica de Rondonópolis (Fig. 9), com litoestratigrafia predominante da Formação Furnas, e presença de solos do tipo Argissolos Vermelho-Amarelo, com vales mais encaixados, indicando topografia mais movimentada, com valores superiores a $13^{\circ}$ e uma hipsometria mais baixa, entre os 450 a $230 \mathrm{~m}$. 


\section{REVISTA GEONORTE}

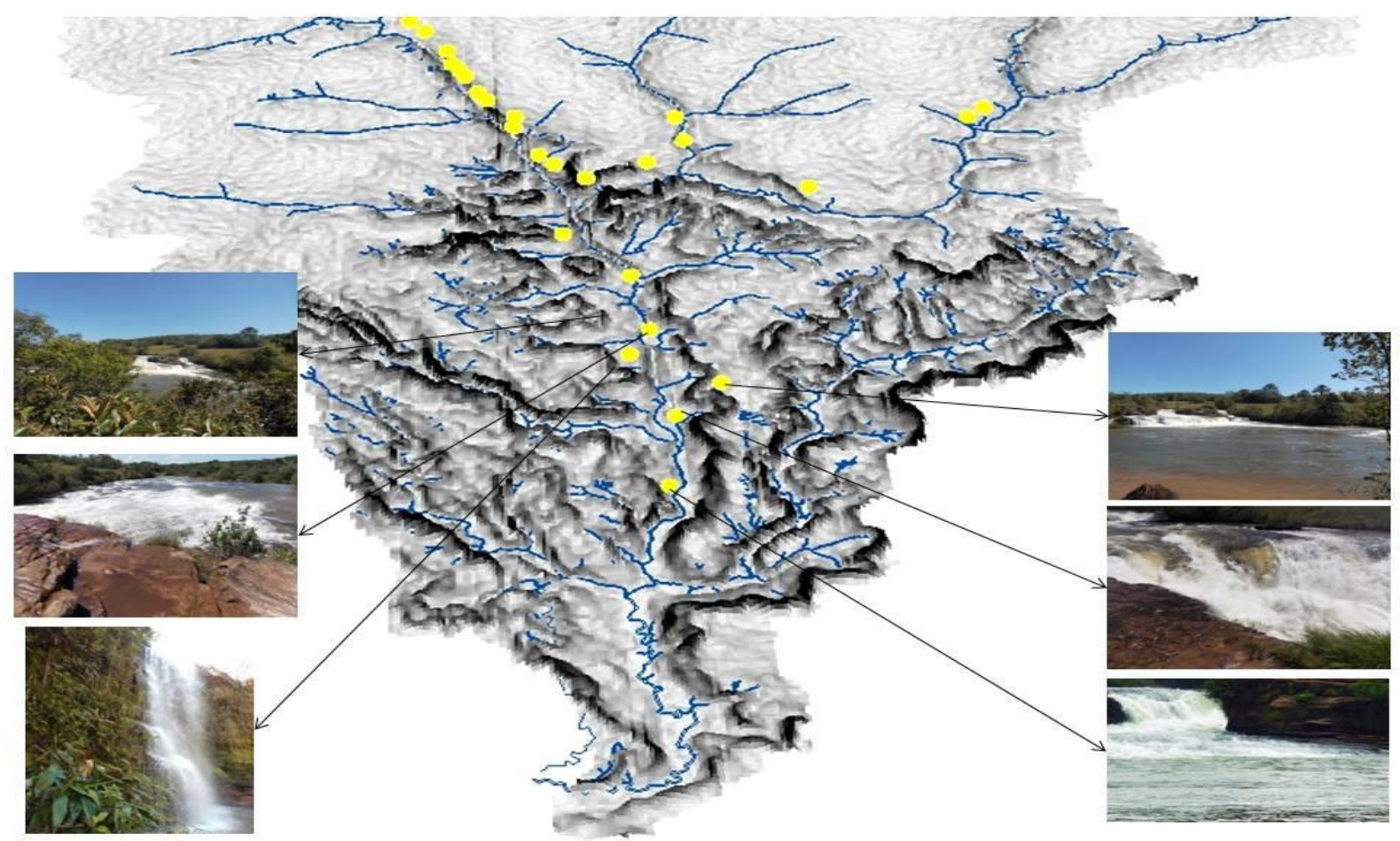

Figura 9 - Distribuição espacial das principais cachoeiras com e sem prática do ecoturismo na bacia hidrográfica do Rio Tenente Amaral. Fonte: Autores.

A geodiveridade nessa categoria levantada é a demais uso e exploração turística encontrada na bacia, de modo que, há diversos empreendimentos de atividades de lazer e do ramo hotelaria/hospedagens/balneários instaladas nos pontos próximos as cachoeiras. Fato que impacta, e ao mesmo tempo demonstra a importância de um levantamento rigoroso e amplo de estudos voltados à compreensão da geodiversidade local, e mais, avaliar integralmente a necessidade da geocorservação de determinados locais nessa área, pois, os pontos estão sobre áreas remontantes nos processos erosivos, e de valor geomorfológico fundamental como testemunhas das ações intempéricas de arrasamento do revelo, e esculpimento dos rios, formando essas cachoeiras com beleza cênica impressionantes.

Os outros elementos avaliados são as fáceis geomorfológicas e geológicas de escarpas e afloramentos de rochas presentes no recorte geográfico analisado, que majoritariamente estão dispostos na Depressão Interplanáltica de Rondonópolis, mediante inclinações superiores a 20 graus, e hipsometria abaixo de 400 metros, com presença transicional entre os depósitos coluvionares e solos do grupo de Argissolos Vermelho-Amarelos, tendo como principal litoestratigrafia a Formação Furnas, e áreas do Grupo Rio Ivaí.

As escarpas encontradas na área apresentam altura de pouco mais de 25 metros, com grande presença de vegetação nativa ou suprimida pela pecuária camponesa, pela proximidade com os cursos d'água e sua posição de delineador dos vales encaixados (Fig. 10), assim, elas ganham conotação de verdadeiros patrimônios dos processos intempéricos e das ações sociais, pois são provas da existência das áreas 
do front de recuo do Planalto dos Guimarães, devido ao trabalho dos rios sob essa morfoescultura (Fig. 11).
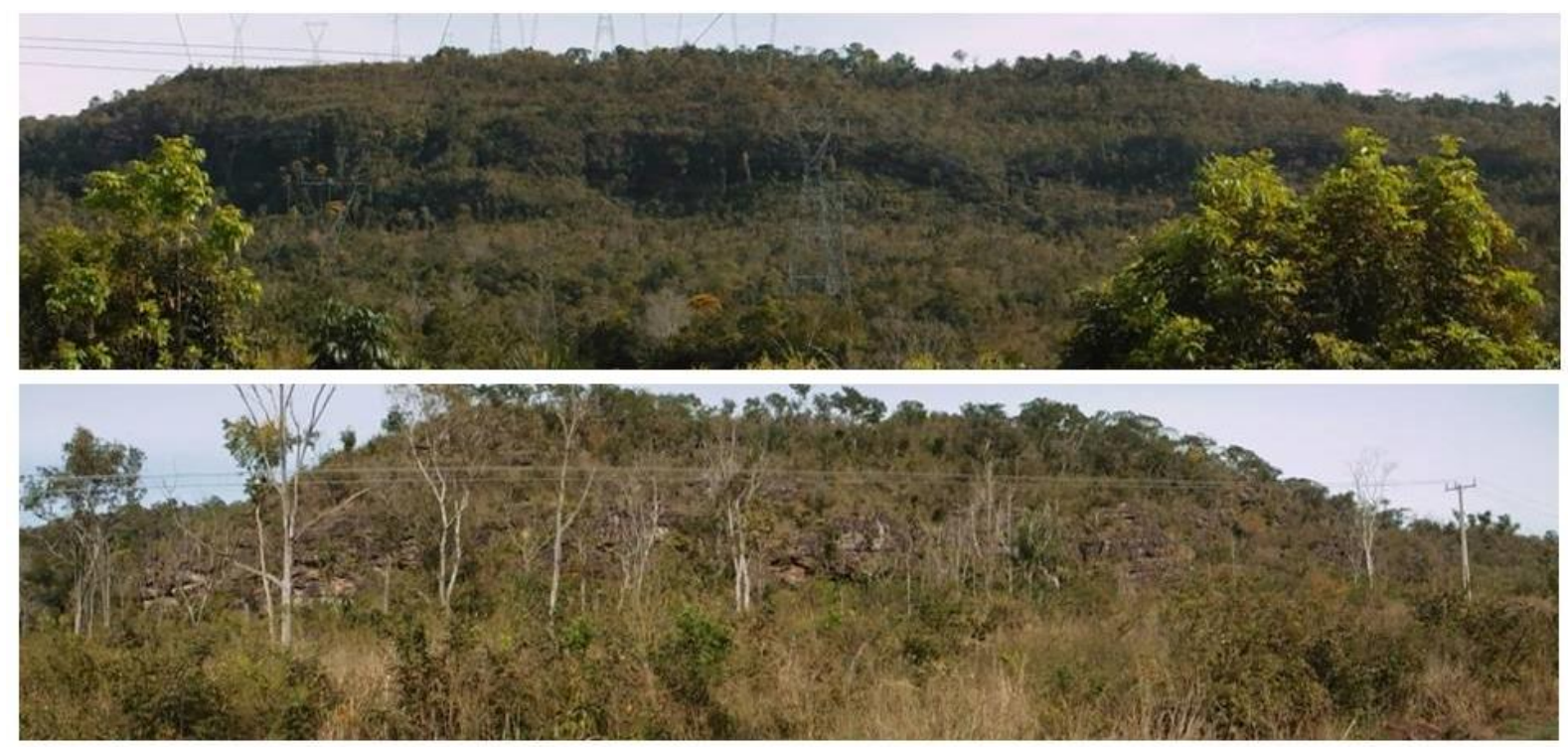

Figura 10: Linhas de escarpas com vegetação nativa delineadoras dos vales encaixados do rio Tenente Amaral. Fonte: Autores.
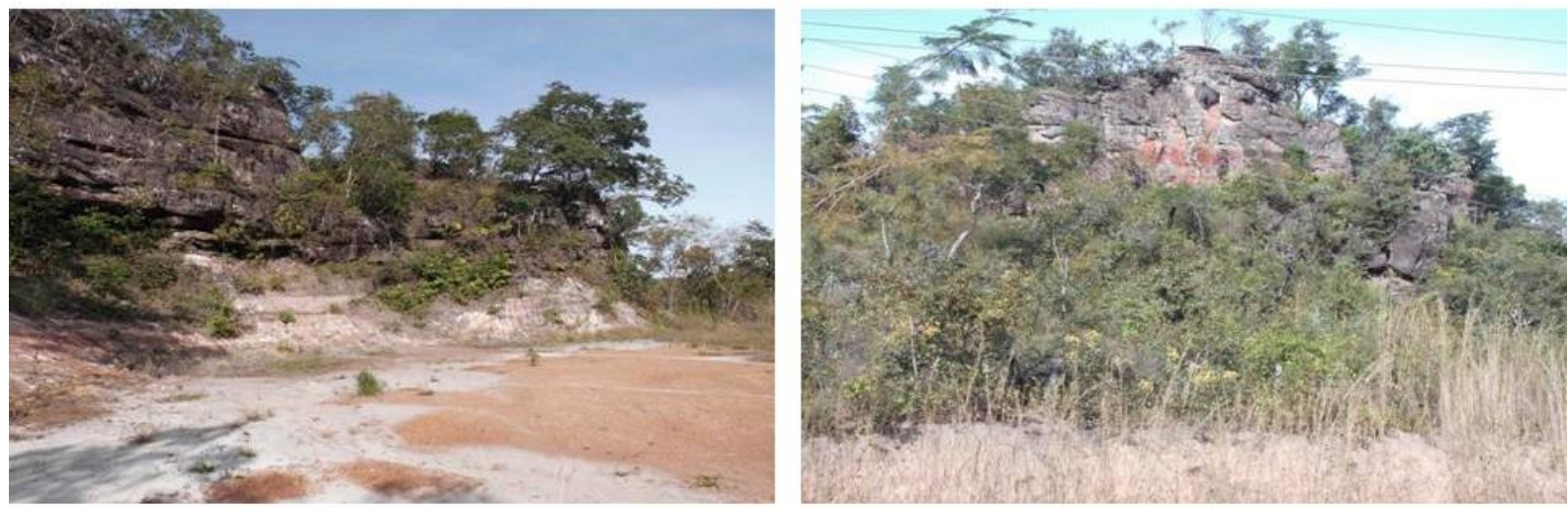

Figura 11 - Escarpas com vegetação nativa de arenito da Formação Furnas, com presença de depósitos coluvionares em seus sopés. Fonte: Autores.

Devido à dimensão da bacia hidrográfica do rio Tenente Amaral ser bem extensa, sua visualização sem obtenção de imageamentossatelitários é muito complicada, mas em sua amplitude há diversas áreas que poderiam ser avaliadas como mirantes de observação do comportamento dos patrimônios presentes nessa área. Possibilitando assim, visitas guiadas e análises mais holísticas dos pontos presentes na linha de visada (Figs. 12 e 13). 


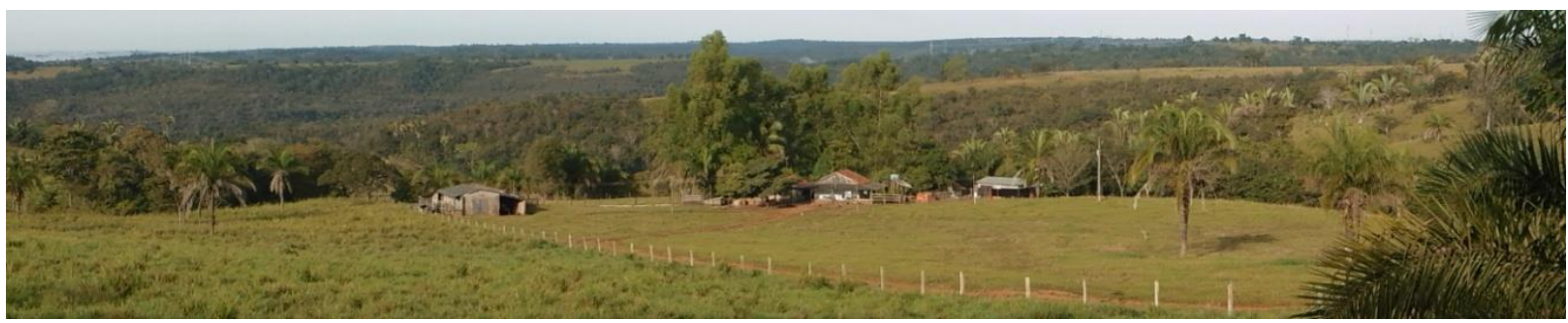

Figura 12: Exemplo de visada de um mirante localizado na extremidade nordeste da bacia, sobre o Grupo Rio Ivaí. Fonte: Autores.

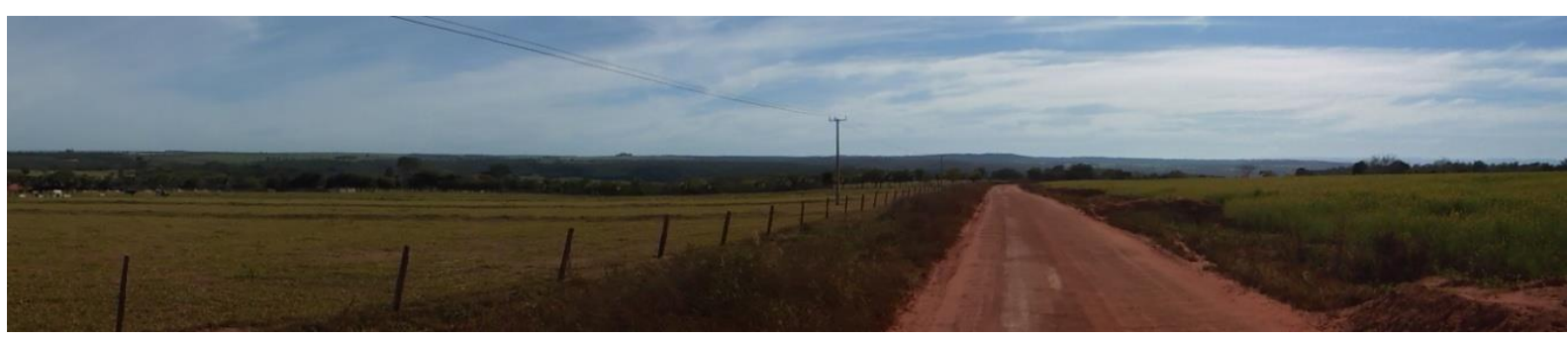

Figura 13 - Exemplo de visada da área de contato entre o Planalto dos Guimarães e a Depressão Interplanáltica de Rondonópolis (Formação Furnas e Grupo Rio Ivaí). Fonte:

Autores.

De modo bem direto essas relações existentes na bacia do rio Tenente Amaral, tendo como base os três eixos de discussão provocam reflexões na compreensão da melhor iniciativa de avaliação de sua geodiversidade.

\section{CONSIDERAÇÕES FINAIS}

A bacia hidrográfica do rio Tenente Amaral apresenta muito potencial para se tornar um território estudado pela ótica da geodiversidade, pois em sua área há diversos geopatrimônios que necessitam de salvaguarda.

O levantamento proposto por esse estudo é preliminar, contudo, são os primeiros passos rumo a estudos mais elaborados, onde de fato, os levantamentos, análises, entrevistas e visitas apresentem maior magnitude da realidade presente, formando um inventariado e inicio de classificações para avaliar os potenciais e determinar as ações de resguardo desses patrimônios.

Assim, os pontos levantados que são predominantemente geomorfológicos são frágeis e necessitam de uma atenção rápida e com qualidade para manterem sua valoração de cunho natural, cientifico - educacional e de belezas impares para toda a sociedade.

Dessa forma, recomendam-se alguns pontos-chaves de ações governamentais e da própria população que usufrui desse patrimônio, tais como:

I. Inventariação completa da geodiversidade da bacia e de seu geopatrimônio;

II. Classificação/valoração do geopatrimônio para proteção e utilização geoturística, com aplicação da Lei no 9.985/2000; 
III. Elaboração de plano de manejo de visitação turística e geoturística (incluindo mapeamento de trilhas interpretativas e guiadas), com capacitação e reciclagem da população local;

IV. Implementação de painéis e placas informativas nas proximidades de cada geopatrimônio.

Torna-se fundamental o planejamento turístico da bacia para divulgar seus belos e importantes atrativos geoturísticos, para que de fato a geoconservação e o desenvolvimento sustentável local possam ser alcançados, dando vida a um dos artigos da Declaração Universal dos Direitos à Memória da Terra.

\section{REFERÊNCIAS}

ALVES, J. E. D. A transição demográfica e a janela de oportunidade. São Paulo, Instituto Fernand Braudel de Economia Mundial. Disponível em: < https://fernandonogueiracosta.files.wordpress.com/2010/08/transicao_demografica.p df. 2008. Acesso em: Agosto de 2017.

BENTO, L. C. M.; RODRIGUES, S. C.Geoturismo em unidades de conservação: uma nova tendência ou uma necessidade real? - estado da arte. Revista do Departamento de Geografia - USP, Volume 25 (2013), p. 77-97.

BORBA, A. W. Geodiversidade e geopatrimônio como bases para estratégias de geoconservação: conceitos, abordagens, métodos de avaliação e aplicabilidade no contexto do Estado do Rio Grande do Sul. Revista Pesquisa em Geociências, v.38, no1; p.3-14, jan/abr. 2011.

BRASIL. DEPARTAMENTO NACIONAL DA PRODUÇÃO MINERAL. PROJETO RADAMBRASIL. Folha SD. 21. Cuiabá. Rio de Janeiro, 1982.

BRASIL. MINISTÉRIO DO TURISMO. Turismo rural: orientações básicas. / Ministério do Turismo, Secretaria Nacional de Políticas de Turismo, Departamento de Estruturação, Articulação e Ordenamento Turístico, Coordenação Geral de Segmentação. - 2.ed - Brasília: Ministério do Turismo, 2010.

BRILHA, J. B. R. Patrimônio geológico e geoconservação - a conservação da natureza na sua vertente geológica. Braga: Palimage, 2005. 190 p.

CAMARGO, L (Org.). Atlas de Mato Grosso: abordagem socioeconômico-ecológica. Cuiabá - MT: Entrelinhas, 2011.

DELPHIM, C.F.M. Patrimônio Cultural e Geoparque. Geologia. USP, Publ. espec., São Paulo, v. 5, p. 75-83. 2009. 
DREW, D. Processos interativos Homem-Meio Ambiente. (Tradução: João Alves dos Santos. Revisão: Suely Bastos). - São Paulo: DIFEL, 1986.

FONTANA, R. C.; MENEGAT, R.; MIZUSAKI, A. M. P. Geoconservação em grandes cidades e proposição dos itinerários geológicos de Porto Alegre: contribuições metodológicas para valoração integrada de unidades geológicas. São Paulo, UNESP, Geociências, v. 34, n. 4, p.897-918, 2015.

GRAY, J. M. Geodiversity: valuing and conserving abiotic nature, 2 nd edn. John Wiley\& Sons, Chichester, 2013.

JESUZ, C. R.; CABRAL, I. L. L. A morfodinâmica da Bacia Hidrográfica do Rio Tenente Amaral - MT. Revista Ra'e Ga, Curitiba, v. 38, p321-344, Dez/2016.

LAMBIN, E. F.; GIBBS, H. K.; FERREIRA, L., GRAU, R.; MAYAUX, P.; MEYFROIDT, P.; MORTON, D. C.; RUDEL, T. K.; GASPARRI, I.; MUNGER, J. Estimating the world's potentially available cropland using a bottom-up approach.Global Environmental Change-Human and Policy Dimensions.23 (5): 892-901, 2013.

LATRUBESSE, E. M., RODRIGUES, S. C., MAMEDE, L. Sistema de classificação e mapeamento geomorfologicos: Uma nova proposta. Geosul. vol. 14 (17), 682-687. 1998.

LÓPEZ-RICHARD, V.; CHINÁGLIA, C. R. Turismo de Aventura: conceitos e paradigmas fundamentais. Turismo em Análise, v. 15, n. 2, p. 199-215, novembro 2004.

NASCIMENTO, M. A. L.; RUCHKYS, Ú. A.; MANTESSO-NETO,V. (Orgs).Geodiversidade, geoconservação e geoturismo: trinômio importante para a proteção do patrimônio geológico. Ed. UFRN, 2008.

OLIVEIRA, P. C. A.; PEDROSA, A. S.; RODRIGUES, S.C. Uma Abordagem Inicial Sobre os Conceitos de Geodiversidade, Geoconservação e Patrimônio Geomorfológico. Revista Ra'e Ga - Curitiba, v.29, p.92-114, dez/2013.

PEREIRA R. G. F. A.; RIOS D. C.; GARCIA P. M. P. Geodiversidade e Patrimônio Geológico: ferramentas para a divulgação e ensino das Geociências. TERRAE DIDATICA 12-3, 196-208, 2016.

PEREIRA, E. O.; RUCHKYS, U. Quantificação e análise da geodiversidade aplicada ao geoturismo na área de proteção ambiental sul da região metropolitana de Belo Horizonte, Minas Gerais. Revista Ra'e Ga - Curitiba, v. 37, p. 207 - 226, Ago/2016.

RUCHKYS, U.A. Patrimônio geológico e geoconservação no Quadrilátero ferrífero, Minas Gerais: potencial para a criação de um Geoparque da Unesco. Instituto de 
Geociências, Universidade Federal de Minas Gerais, Belo Horizonte, Tese de Doutorado, 2007, 211p.

SERVIÇO GEOLÓGICO DO BRASIL (CPRM). Geodiversidade do Brasil: conhecer o passado para entender o presente e prever o futuro. Rio de Janeiro: CPRM, 2008.

SILVA, B. B.; GOMES, H. B.; SILVA, S. T. A. Alterações climáticas decorrentes de mudanças no uso da terra mediante sensoriamento remoto. Mercator (Fortaleza. Online), v. 9, p. 91-106, 2010.

SILVA, J.M.F.; GÂNDARA, J.M.G. Geotecnologia aplicada à conservação, divulgação e uso de atrativos geoturísticos de Prudentópolis (PR). Revista Brasileira de Ecoturismo, São Paulo, v.7, n.2, maio/jul 2014, pp.374-393.

SOUZA, A. S.; LUCENA, M. M. A.; NASCIMENTO, M. A. L. Caracterização da geodiversidade de um sítio arqueológico: potencialidades para o geoturismo e geoconservação. In: SEABRA, G.(Organizador). Terra - paisagens, solos, biodiversidade e os desafios para um bom viver. Ituiutaba: Barlavento, 2016. 1568p.

TARIFA, J. R. Mato Grosso: clima: análise e representação cartográfica. (Série recursos naturais e estudos ambientais). Cuiabá, MT: Entrelinhas, 2011.

VASCONCELOS, T. N. N. Interpretação morfopedológica da Bacia do Rio Tenente Amaral - Jaciara/MT: condição básica para sua caracterização ambiental. Cuiabá, 1998.162 p. Dissertação (Mestrado). Universidade Federal de Mato Grosso, Cuiabá 1998.

WWF- BRASIL. Monitoramento das alterações da cobertura vegetal e uso do Solo na Bacia do Alto Paraguai - Porção Brasileira - Período de Análise: 2012 a 2014. Iniciativa: Instituto SOS Pantanal, WWF- Brasil. Brasília, 2015. 